\section{Relationship between Flowering and Heat Units to Analyze Crop Efficiency of Olive Cultivars Located in Southern Italy}

\author{
Fabio Orlandi, Bruno Romano, and Marco Fornaciari \\ Department of Plant Biology and Agroenvironmental Biotechnology, University \\ of Perugia, Borgo XX Giugno 74-06121 Perugia Italy
}

Additional index words. Olea europaea L., pollen monitoring, GDH-GDD, climate

Abstract. The relationship between heat units trends and reproductive development in olive (Olea europaea, L.) was studied over a 3-year period (1999-2001) in 15 areas in the southern Italian regions of Campania, Calabria, Puglia, and Sicily. Heat units were calculated using GDH and GDD formulas and the flowering phases in the olive groves were studied using volumetric pollen traps that aspirate fixed quantities of air. With this method, the olive pollen release and flowering trends were determined. The main objective of the study was to correlate the spring heat unit amounts and the phases of maximum pollen emission with the date of flowering. Moreover, the ranges of GDH and GDD in the different study areas were calculated to identify maps of olive pollen release.

This study was undertaken to investigate the relationship between heat units trends and reproductive development in olive (Olea europaea L.). In recent years there has been increasing interest in olive research due to health-related importance of oil, as well as in bioclimatic research (Bonhomme, 2000; Malet et al., 1997). Many studies have investigated the relationship between climate and flowering phases in different species (Galan et al., 2001; Lechowicz, 1995; Pellizzaro et al., 1996) and have shown the relationship between the accumulated heat requirements and the consequent phases of pollen maturation and release (Fornaciari et al., 1998). This study, conducted over a 3-year period (1999-2001) evaluated the relationship between spring temperatures, expressed as GDH and GDD, and the flowering phases, defined as the pollen emission period, in some olive cultivars.

The main objective was to evaluate and to interpret the biological response of some olive cultivars to climatic variations and to draw olive flowering maps in the areas of interest to synchronize their pollination and fertilization considering the self-sterility problem for many olive cultivars.

The olive flowering phases were studied using the aerobiological methodology with the use of volumetric pollen traps that aspirated fixed quantities of atmosphere, from which the exact volume aspirated over a certain period of time could be determined.

\section{Materials and Methods}

The pollen emission data for olive were collected continuously over a 3-year period (1999-2001), using solar-powered volumetric pollen traps (Fig. 1) placed in fifteen monitoring stations located in four regions in southern Italy (Campania, Calabria, Puglia, and Sicily where about $35 \%$ of the world olive crop is

Received for publication 17 Dec. 2002. Accepted for publication 29 Dec. 2003. a pollinator. The oil of 'Coratina' has a very high polyphenol content. 'Biancolilla' was found in two areas, while the other cultivars (Minuta, Ogliarola, Peranzana, Cellina di Nardò, Carolea and Ortolana) were found only in one area. 'Biancolilla' is resistant to low temperatures and is partially self-sterile. Its yield is improved in the presence of pollinators like 'Moresca' and 'Ogliarola'.

The trap (VPPS 2000 Lanzoni model, Lanzoni s.r.l., Bologna, Italy) based on the design of the Hirst model (Hirst, 1952), is made up of two parts: a lower fixed part, and an upper mobile part. A constant air flow volume (10 $\mathrm{L} \cdot \mathrm{min}^{-1}$ ), which contains the airborne material, passes through the aperture. The airborne particles stick to a drum that revolves at a rate of $2 \mathrm{~mm} \cdot \mathrm{h}^{-1}$. A 7-d transparent adhesive strip was fixed on the drum (Melinex with silicone oil); once removed, this strip was cut into seven pieces, corresponding to the days of the week, and mounted on microscope slides for identification and counting (Ogden et al., 1974). By knowing the volume of air that enters, the concentration of particles per cubic meter can be expressed hourly, daily or weekly (Fornaciari et al., 1998; Gagnon and Comtois, 1992; Tomas et al., 1997).

The data collected were used to calculate the daily pollen concentrations in the air, and subsequently, to construct a complete emission spectrum (Fornaciari et al., 2000). For each geographic area studied, the day was determined when the olive pollen was first recorded; this was considered the start of the flowering phase. Moreover, the day on which the maximum pollen concentration occurred was determined. These two dates (the starting and maximum pollination days) were used to describe the relationship between heat units amount and the principal flowering phase (Chuine et al., 1999).

The heat units were calculated using

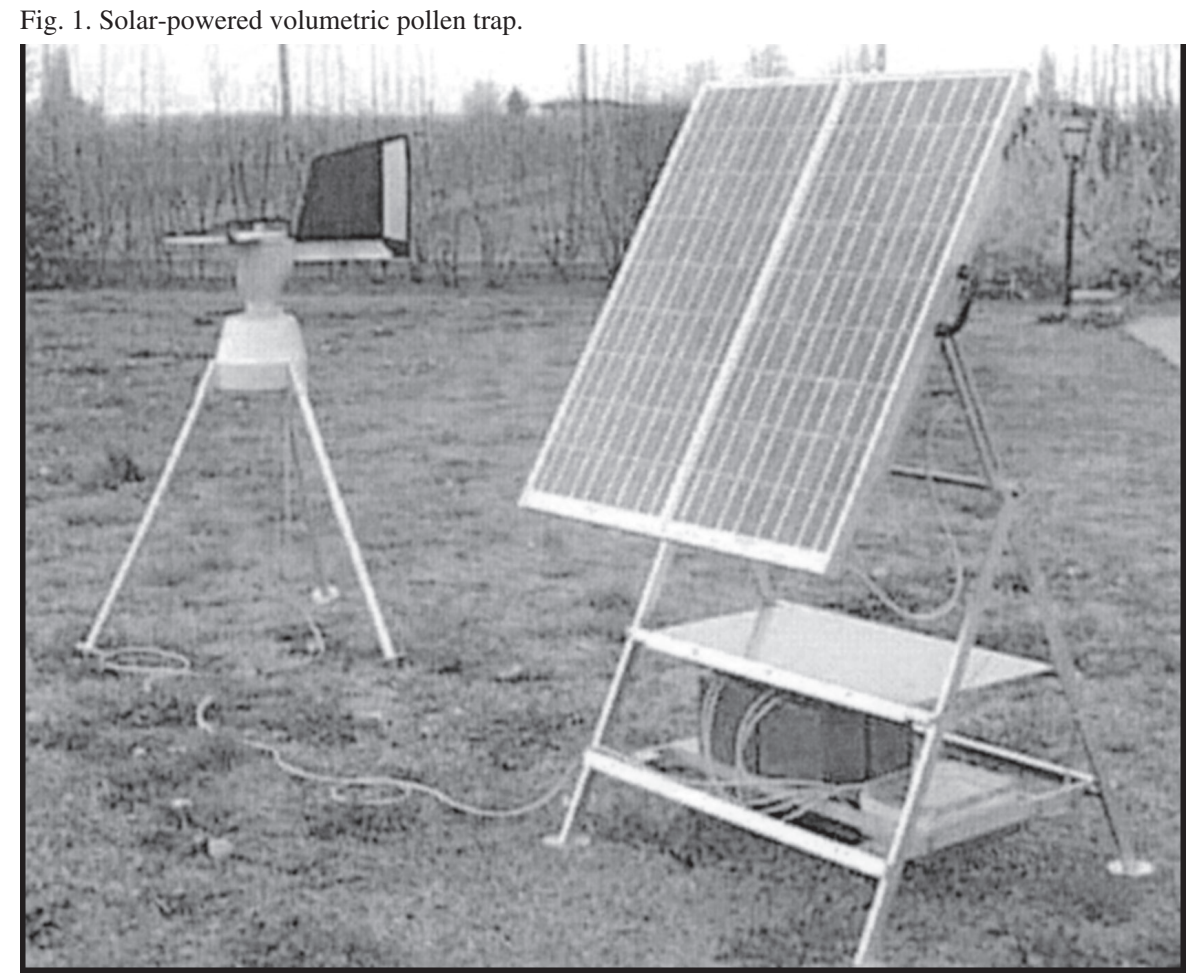


Table 1. Olive grove areas and principal olive cultivars in 4 regions of southern Italy.

\begin{tabular}{lll}
\hline Region & Olive areas & Olive cultivars \\
Sicily & Agrigento & Biancolilla \\
& Messina & Minuta \\
& Palermo & Ogliarola \\
& Trapani & Biancolilla, Giarraffa \\
\cline { 2 - 3 } Puglia & Bari & Coratina, Ogliarola \\
& Brindisi & Coratina, Ogliarola \\
& Foggia & Peranzana \\
& Lecce & Cellina di Nardò, Carolea \\
& Taranto & Cellina di Nardò, Carolea \\
\cline { 2 - 3 } Calabria & Catanzaro & Carolea \\
& Cosenza & Leccino, Coratina \\
& Reggio C. & Leccino, Coratina \\
\cline { 2 - 3 } Campania & Avellino & Leccino, Olivella \\
& Benevento & Ortolana, Auliviello \\
& Salerno & Frantoio, Rotondella
\end{tabular}

growing degree hours (GDH) and growing degree days (GDD) formulas which supplied daily temperature values (Caruso et al., 1992; Spano et al., 1999). The GDH formula was calculated using the hourly temperatures (Anderson et al. 1986), while the GDD equation was calculated on the basis of the daily maximum and minimum temperatures using twenty threshold temperatures (TT) between 1 and $20^{\circ} \mathrm{C}$ (GDD1; GDD2...; GDD20). For each monitoring station, 21 yearly heat units amounts (GDH + 20 GDD) were derived from $1 \mathrm{Jan}$. to the day when airborne pollen was first recorded, and another 21 from 1 Jan. to the day when the maximum pollen concentration was recorded.

To calculate the GDH and GDD values, temperature data were obtained from the fifteen weather stations of the National Agrometeorological Network that are located near the respective pollen monitoring sites.

To determine the relationship between heat units amounts and pollen release, two-way analyses of variance (ANOVA) were carried out, using the GDD-GDH amounts from all 15 stations calculated for each TT over the 3 year period. Four specific analyses by ANOVA were carried out in which the monitoring stations were grouped according to regions, while other ANOVA were done for each of the areas where the same olive cultivars were planted; this was done to test the flowering response of genetically similar trees.

\section{Results}

Airborne olive pollen was first recorded between the last week of April and the first week of May and persisted until June (Fig. 2 ). Flowering began first in the southern-most study sites in Sicily, followed by those in the southern part of Puglia and then the other sites in Puglia, Calabria, and Campania. Evidently the range of days in which maximum pollen concentration was recorded in the 3 years was smaller than the range of days in which the presence of airborne olive pollen was first recorded.

Moreover it is also evident that both the initial and maximum pollen concentration dates were earlier at all the monitoring stations in 2000 and for most stations in 2001 (Fig. 2).

Table 2 presents the results of the ANOVA in which all the monitoring stations were grouped together. The results show the effect of years and monitoring stations on the heat units amounts calculated until starting and maximum daily pollen concentration. The series of results that was obtained considering the day of the first airborne pollen was recorded is quite distinct in comparison to the series obtained using data regarding the dates on which the maximum pollen concentrations were recorded. In the first case the variance rates ( $\mathrm{F}$ and $p$ value) of the different TT determine a particular and useless trend according to which the use of higher TT $\left(>10^{\circ} \mathrm{C}\right.$.) always produce smaller variances in the amounts. On the other hand, the ANOVA results considering the max pollination day evidence the $\mathrm{p}$-values for the two factors as insignificant, and only considering the GDD with TT included between 9 to $13{ }^{\circ} \mathrm{C}$ the $p$ values were significant (Table 2 ).

The diagnostic tests related to the GDD12 ANOVA with max day of pollination were carried out and shown in Fig. 3. In particular a histogram of the residuals shows a quite normal distribution, the linearity of the normal QQ-plot shows that the distribution is normal in the middle, moreover the plot of the residuals versus fit indicates that a smaller error variance is associated with larger values of fit (300 to 400 GDD).

As a consequence of this result, another series of two-way ANOVA analyses were performed using only the GDD12 formula with the maximum pollination day and grouping the 15 monitoring stations according to region. In Table 3 the significant $p$ values are evident, for each of the four regions, the $p$ values related to years were significant, while when considering the monitoring stations these values were only significant for Puglia and Calabria. In Table 4 , the results are shown for three groups that were based on areas in which the same olive cultivars were found. The heat units amounts were recorded in the first group of monitoring stations which included Cosenza, Reggio Calabria, and Avellino, where the principal olive cultivar was 'Leccino'. The second group included the areas of Bari and Brindisi in which ' $\mathrm{Co}$ ratina' and 'Ogliarola' were found and the third group included Agrigento and Trapani which had 'Biancolilla'. In all the analyses by ANOVA, the $p$ values related to the 3 years as a factor were high, demonstrating the annual similarity of the relationship between heat units amount and biological response in plants in the same cultivar. In the second group (Bari, Brindisi) a high $p$ value related to the monitoring station factor was recorded which indicates the similarity between these locations.

Three sets of graphs are presented in Fig. 4 to show the pollen emission in areas with the same cultivar. In the monitoring stations of Bari and Brindisi (Fig. 4A) there is a close synchrony with little variation in the days between peak pollen emission due to the similar climatic conditions of these two areas that are located near each other.

In the second set of graphs (Fig. 4B), for the stations of Agrigento and Trapani, the differences in the heat units amounts between the stations are clear $(p=0.02)$, while the differences among the 3 years were not significant ( $p=0.68$ ). Moreover, in these two areas, with a single cultivar ('Biancolilla'), the clear evidence of pollination peaks and heat unit amount differences, showed that flowering was not only regulated by heat unit amounts but, also by photoperiod, as indicated in other studies (Erez et al., 1966; Preston and Haun 1963).

The third set of graphs (Fig. 4C) shows the performance of the Leccino cultivar which was found in three areas located at different

Fig. 2. Dates in which the first and maximum pollen concentrations were observed by the pollen traps in every monitoring stations in the 3 years of study.

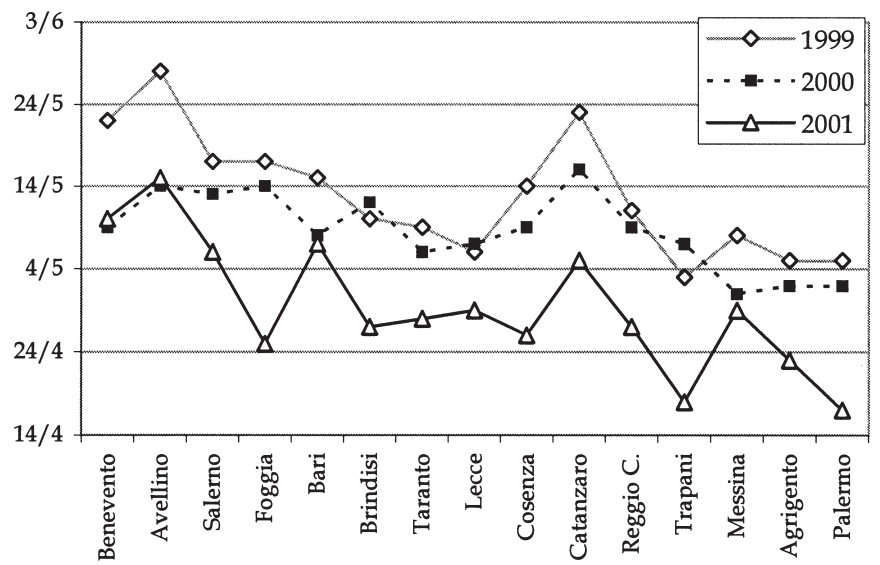

Dates where the maximum pollen concentrations were recorded

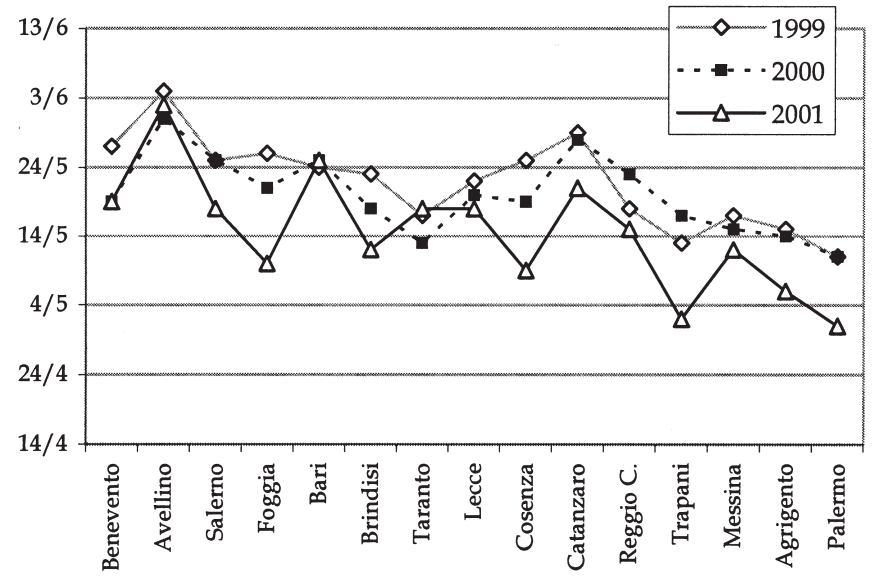


latitudes $($ Avellino $=41.78$ north; Cosenza $=$ 39.67 north $;$ Palmi $=38.35$ north). Neither heat unit trends nor photoperiod could harmonize the attributes of different stations, and thus, statistically significant differences in heat unit amounts were obtained due to the geographic factor $(p=0.00)$. The heat unit amount similarities among different years were due to the genetic characteristics of the cultivar.

The heat unit amount response was evident Table 2. Two-way ANOVA results for the day of first and maximum pollination.

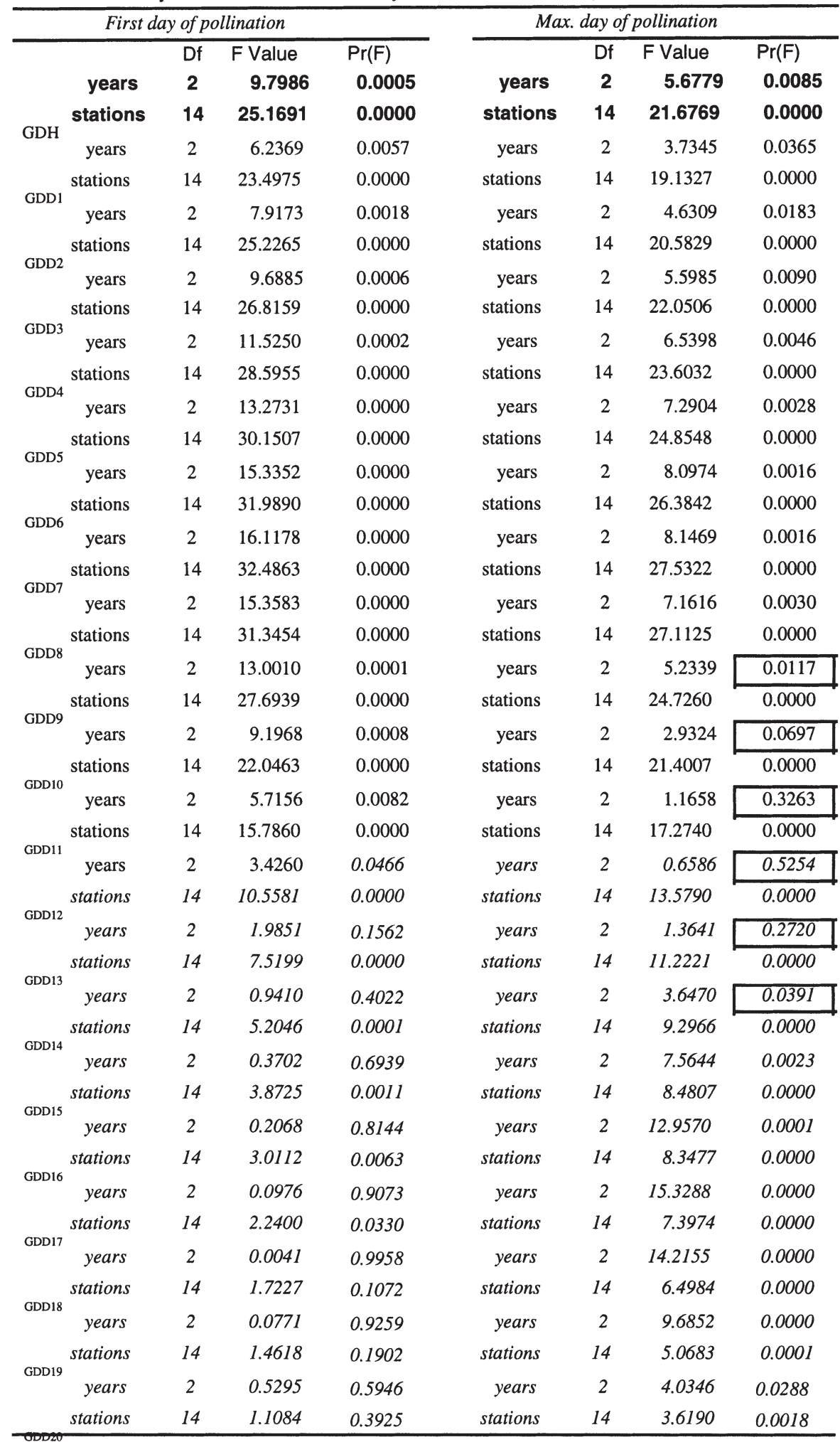

for all the monitoring stations, in fact in 2001 it began to accumulate GDD earlier than in 2000 which, was earlier than 1999. At 10 monitoring stations (Agrigento, Catanzaro, Cosenza, Foggia, Lecce, Messina, Palermo, Reggio C., Taranto, Trapani) the relations between heat unit amount trends continued until the range of GDD values was sufficient to reach the maximum flowering (Fig. 5), while at five stations (Avellino, Bari, Benevento, Brindisi, Salerno) the heat unit amounts of 2000 and temperatures of 2000 and 2001 were evident, only the olive cultivar Minuta in Messina did not have an earlier flowering. This indicates that 'Minuta' was not particularly sensitive to the variations in temperature.

\section{Discussion}

Based on the statistical analyses, the best formula for calculating the relationships between heat unit amount and olive flowering is the GDD with a $12{ }^{\circ} \mathrm{C}$ threshold temperature (GDD12) considering the day of maximum pollen concentration as the final date.

Maximum pollen concentration days show the least variance. This is probably due to the fact that these dates are subject to less variation while it is difficult to identify the first day when pollen was recorded which may be influenced by false start phenomena, caused by marked heat unit variations. On the other hand, the geographic factor (15 monitoring stations) did not affect the relationship between climate and flowering. Consequently, the differences
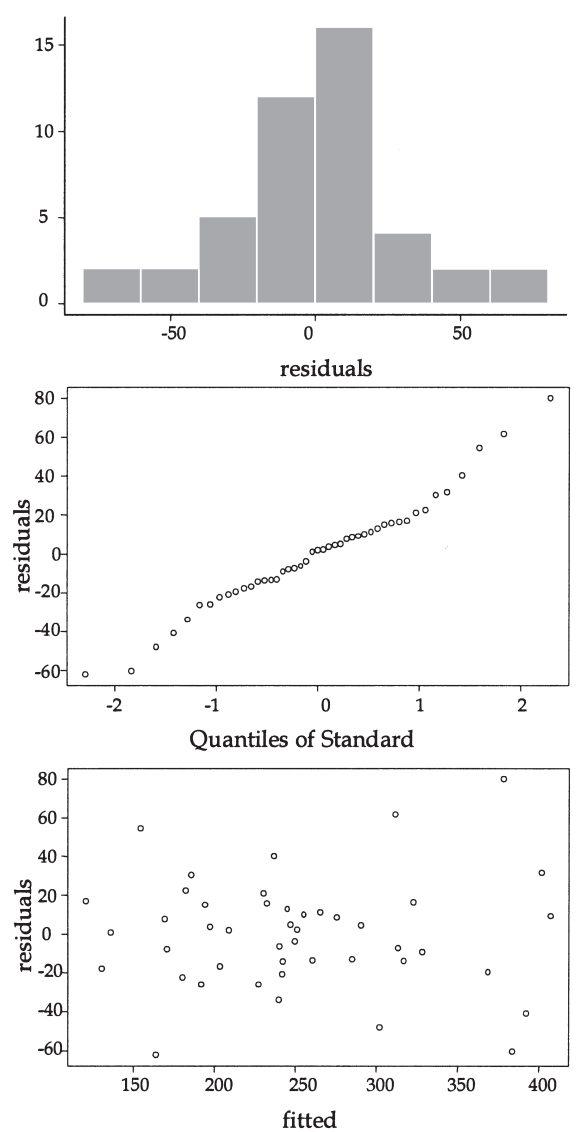

Fig. 3. Diagnostic tests of the two-way ANOVA. 
Table 3. ANOVA results for GDD $\left(12^{\circ} \mathrm{C}\right.$. T.T. $)$ in the 4 regions.

\begin{tabular}{|c|c|c|c|c|c|}
\hline \multicolumn{6}{|c|}{ First day of pollination } \\
\hline & Df & Sum of $\mathrm{Sq}$ & Mean Sq & F Value & $\operatorname{Pr}(\mathbf{F})$ \\
\hline years & 2 & 22762 & 11381 & 29.4626 & 0.0040 \\
\hline stations & 2 & 22534 & 11267 & 29.1675 & 0.0041 \\
\hline Residuals & 4 & 1545 & 386 & & \\
\hline \multirow{3}{*}{$\begin{array}{c}\text { stations } \\
\text { PUGLIR Residuals }\end{array}$} & 2 & 16806 & 8403 & 0.9004 & 0.4439 \\
\hline & 4 & 122557 & 30639 & 3.2831 & 0.0716 \\
\hline & 8 & 74660 & 9333 & & \\
\hline years & 2 & 300 & 150 & 0.1073 & 0.9007 \\
\hline stations & 2 & 187736 & 93868 & 67.2597 & 0.0008 \\
\hline Residuals & 4 & 5582 & 1396 & & \\
\hline $\begin{array}{l}\text { CALABRIA } \\
\text { years }\end{array}$ & 2 & 40986 & 20493 & 13.2311 & 0.0063 \\
\hline stations & 3 & 437897 & 145965 & 94.2408 & 0.0000 \\
\hline SICILIResiduals & 6 & 9293 & 1548 & & \\
\hline \multicolumn{6}{|c|}{ Max. day of pollination } \\
\hline & Df & Sum of Sq & Mean Sq & F Value & $\operatorname{Pr}(\mathrm{F})$ \\
\hline years & 2 & 14802 & 7401 & 10.6950 & 0.0248 \\
\hline stations & 2 & 74594 & 37297 & 53.8974 & 0.0013 \\
\hline Residuals & 4 & 2768 & 692 & & \\
\hline years & 2 & 40567 & 20283 & 1.7418 & 0.2355 \\
\hline stations & 4 & 166808 & 41702 & 3.5811 & 0.0588 \\
\hline PUGLIA ${ }^{\text {Residuals }}$ & 8 & 93161 & 11645 & & \\
\hline years & 2 & 2966 & 1483 & 0.3996 & 0.6946 \\
\hline stations & 2 & 199440 & 99720 & 26.8647 & 0.0048 \\
\hline Residuals & 4 & 14847 & 3711 & & \\
\hline $\begin{array}{l}\text { CALABRIA } \\
\text { years }\end{array}$ & 2 & 12086 & 6043 & 2.7233 & 0.1440 \\
\hline stations & 3 & 455334 & 151778 & 68.4002 & 0.0000 \\
\hline SICILIA Residuals & 6 & 13313 & 2219 & & \\
\hline
\end{tabular}

Table 4. ANOVA results for GDD $\left(12^{\circ} \mathrm{C}\right.$. T.T. $)$ in areas

with the same olive cultivars.

\begin{tabular}{cccccc}
\hline $1^{\circ}$ Group & $\begin{array}{c}\text { (COSENZA, REGGIO CAL. AVELLINO) } \\
\text { Df }\end{array}$ & \multicolumn{5}{c}{ Sum of Sq } & Mean Sq & F Value & $\operatorname{Pr}(\mathrm{F})$ \\
years & 2 & 5584 & 2792 & 0.5770 & 0.6023 \\
stations & 2 & 231524 & 115762 & 23.9213 & 0.0059 \\
Residuals & 4 & 19357 & 4839 & &
\end{tabular}

\section{$2^{\circ}$ Group (BARI, BRINDISI)}

$\begin{array}{cccccc}\text { years } & 2 & 17052 & 8526 & 0.4253 & 0.7016 \\ \text { stations } & 1 & 2563 & 2563 & 0.1278 & 0.7548\end{array}$

Residuals $\quad 2 \quad 40094 \quad 20047$

$3^{\circ}$ Group (AGRIGento, TRAPANI)

\begin{tabular}{cccccc} 
years & 2 & 3554 & 1777 & 0.4601 & 0.6848 \\
stations & 1 & 151686 & 151686 & 39.2714 & 0.0245 \\
Residuals & 2 & 7725 & 3863 & & \\
\hline
\end{tabular}

two monitoring stations, as shown in Fig. 4 , were much earlier in comparison to the other years and so potentially improved the olive yield in that year.

In conclusion, the evidence of a close relationship between olive cultivars and climatic factors permits one to analyse and optimize olive grove planning

between the olive-grove areas were statistically significant in relation to the heat unit amounts, and were considered random.

The results for the GDD12 with the maximum pollination day, indicate that the differences between the years in each of the four regions, were not significant. Moreover, in two regions (Puglia and Calabria) even the differences among various monitoring areas were not statistically significant which indicates a sufficiently homogenous relationship between the climate and olive trees. This conclusion concurs with the data according to which the agronomic techniques for olive cultivation in Puglia have been improved to reduce the typical alternate yearly production with a relative standardization of the annual yield. On the other hand, it can be assumed that the olive areas in this region are subject to similar climatic conditions due to the mitigating effect of the Adriatic Sea.

The ANOVA results from the monitoring stations characterized by the same olive cultivars indicated that since the climate-flowering relationships were very close in these particular conditions it was possible to exactly map pollen release phenomena.

In relation to the heat unit amount behaviours, it is evident that, by knowing the trends and considering that the later flowering is linked to a poor fruit set (Fornaciari et al., 2002), in the month before pollination it is possible to predict the potential olive production level in comparison to the annual average. The heat unit amount trends for 2001 from the first (the choice of the more synchronous cultivars in comparison with the specific meteorological conditions in the area) and the agronomic techniques. Moreover the possibility of having a preforecasting tool related to the future olive harvest could be useful for conducting different operations during the summer, such as pruning and irrigation which effect olive production costs.

\section{Literature Cited}

Anderson, J.L., E.A. Richardson, and C.D. Kesner. 1986. Validation of chill unit and flower bud phenology models for 'Montmorency' sour cherry. Acta Hort. 184:71-78.

Bonhomme, R. 2000. Bases and limits to using "degree day" units. Euro. J. Agron. 13:1-10.

Caruso, T., A. Motisi, F.P. Marra, and E. Barone. 1992. The use of phenoclimatic models to characterize environments for chilling and heat requirements of deciduous fruit trees: Methodological approaches and initial results. Adv. Hort. Sci. 6:65-73.

Chuine, I., P. Cour, and D.D. Rousseau. 1999. Selecting models to predict the timing of flowering of temperate trees: Implications for tree phenology modelling. Plant Cell Environ. 22:1-13.

Erez, A., R.M. Samish, and S. Lavee. 1966. The role of light in leaf and flower bud break of the Peach (Prunus persica). Physiol. Plantarum 19:650-659.

Fornaciari, M., L. Pieroni, P. Ciuchi, and B. Romano. 1998. A regression model for the start of the pollen season in Olea europaea L. Grana 37:110-113.

Fornaciari, M., D. Lanari, F. Orlandi, L. Pieroni, P. Polinori, E. Tedeschini, and B. Romano. 2000. 


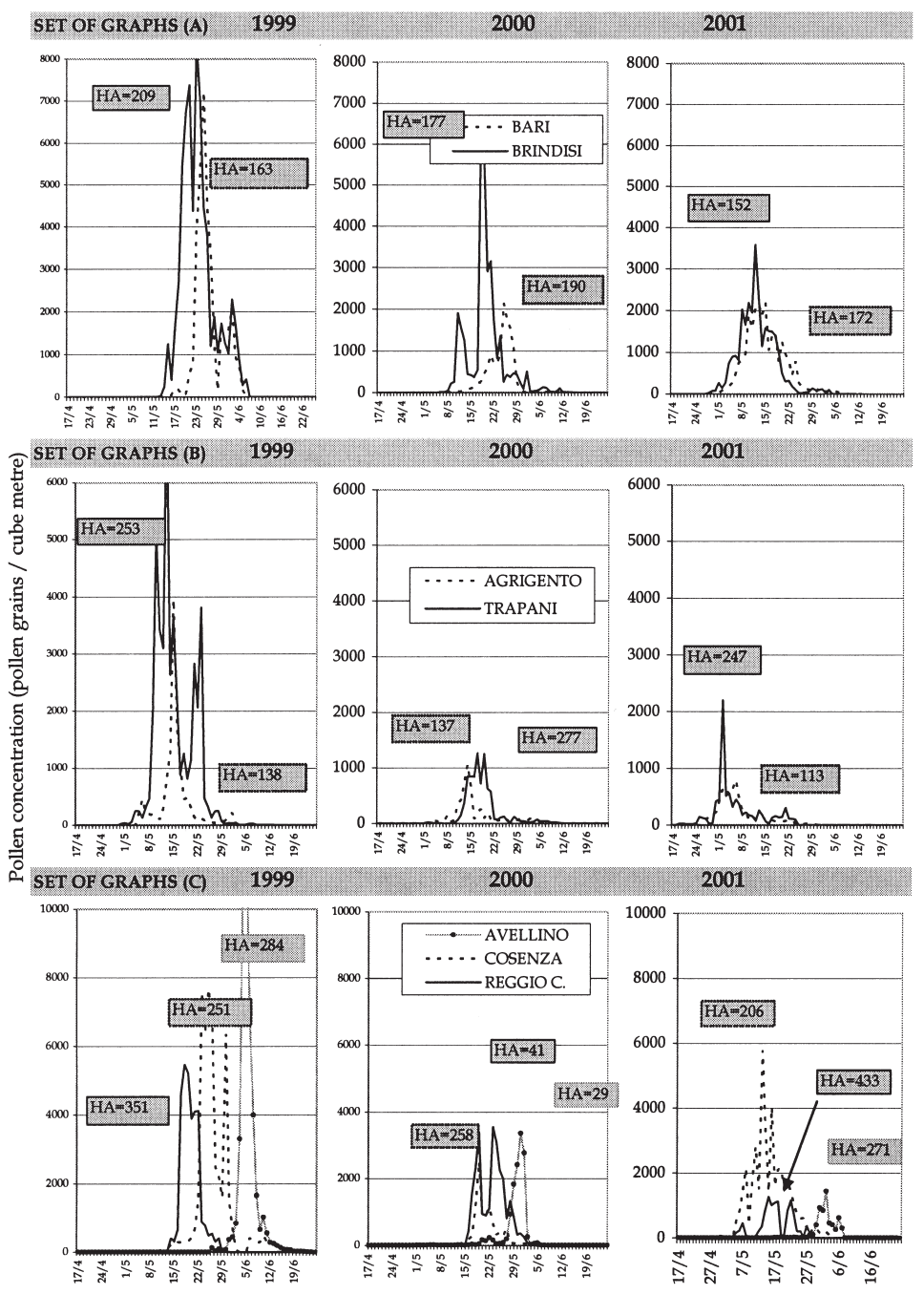

Fig. 4. Daily pollen emissions in three areas (different sets of graphs) with same olive cultivars. $\mathrm{HA}=$ heat unit amounts.

P.O.M. A31. Progetto per la realizzazione e sperimentazione di una rete multiregionale per le previsioni di raccolta della produzione olivicola-Anno 1999. Dipartimento di Biologia vegetale e Biotecnologie Agroambientali, Università di Perugia. Perugia, Maggio 2000.

Fornaciari, M., L. Pieroni, F. Orlandi, and B. Romano. 2002. A new approach to consider the pollen variable in forecasting yield models. Econ. Bot. 56(1):66-72.

Gagnon, L. and P. Comtois. 1992. Peut-on comparer les résultats de differents types de capteurs polliniques? Grana 31:125-130.

Galán, C., H. García-Mozo, P. Cariñanos, P. Alcázar, and E. Domínguez. 2001. The role of temperature in the onset of the Olea europaea L. pollen season in southwestern Spain. Intl. J. Biometeorol. 45:8-12.

Hirst, J.M. 1952. An automatic volumetric spore trap. Ann. Appl. Biol. 39:257-265.

Lechowicz, M.J. 1995. Seasonality of flowering and fruiting in temperature forest trees. Can. J. Bot. 73:175-182.

Malet, P., F. Pecaut, and C. Bruchou. 1997. Beware of using cumulated variables in growth and de- velopment models. Agr. For. Met. 88:137-143.

Ogden, E.C., G.S. Raynor, G.V. Hayes, D.M. Lewis, and J.H. Haines. 1974. Manual for sampling airborne pollen. Hafner Press, New York.

Pellizzaro, G., D. Spano, A. Canu, and C. Cesaraccio. 1996. Calcolo dei gradi-giorno per la previsione delle fasi fenologiche nell' actinidia. Italus Hortus 3:24-30.

Preston, W.H. and J.R. Haun. 1963. Relationship of temperature and photoperiod to growth, flowering, senescence and dormancy of Dioscorea spiculiflora. Bot. Gaz. 124:346-353.

Spano, D., C. Cesaraccio, D. Duce, and R.L. Zinder. 1999. Phenological stages of natural species and their use as climate indicators. Intl. J. Biometeorol. 42:124-133.

Tomas, C., P. Candau, and F.J. Gonzalez Minero. 1997. A comparative study of atmospheric pollen concentrations collected with Burkard and Cour samplers, Seville (Spain), 1992-1994. Grana 36:122-128. until the maximum pollen concentration dates in
und the 3 years of study. Threshold level corresponds to two-thirds of the average heat unit amounts at the maximum pollen concentrations (shown in the circles). 